\title{
The genetic constituent of varicose vein pathogenesis as a key for future treatment option development
}

\author{
Mariya A. Smetanina ${ }^{1,2}$, Andrey I. Shevela ${ }^{3,4}$, Konstantin A. Gavrilov, ${ }^{3,4}$, Maxim L. Filipenko ${ }^{1,5}$ \\ 'Laboratory of Pharmacogenomics, Institute of Chemical Biology and Fundamental Medicine (ICBFM) SB RAS, Novosibirsk \\ 630090, Russia. \\ ${ }^{2}$ Department of Fundamental Medicine, V. Zelman Institute for Medicine and Psycology (NSU), Novosibirsk 630090, Russia. \\ ${ }^{3}$ Center of New Medical Technologies, Institute of Chemical Biology and Fundamental Medicine (ICBFM) SB RAS, Novosibirsk \\ 630090, Russia. \\ ${ }^{4}$ Department of Surgical Diseases, V. Zelman Institute for Medicine and Psycology (NSU), Novosibirsk 630090, Russia. \\ ${ }^{5}$ Department of Clinical Biochemistry, V. Zelman Institute for Medicine and Psycology (NSU), Novosibirsk 630090, Russia.
}

Correspondence to: Dr. Mariya A. Smetanina, Laboratory of Pharmacogenomics, Institute of Chemical Biology and Fundamental Medicine (ICBFM) SB RAS, 8 Lavrentiev Avenue, Novosibirsk 630090, Russia. E-mail: mariya_smetanina@niboch.nsc.ru

How to cite this article: Smetanina MA, Shevela Al, Gavrilov KA, Filipenko ML. The genetic constituent of varicose vein pathogenesis as a key for future treatment option development. Vessel Plus 2021;5:19. https://dx.doi.org/10.20517/25741209.2021.17

Received: 31 Jan 2021 First Decision: 1 Mar 2021 Revised: 15 Mar 2021 Accepted: 24 Mar 2021 Available online: 17 Apr 2021

Academic Editor: Alexander D. Verin Copy Editor: Yue-Yue Zhang Production Editor: Yue-Yue Zhang

\begin{abstract}
This perspective focuses primarily on the fundamental part of phlebology, where most attention is paid to the genetic aspects of the pathogenesis of varicose vein disease and where the main breakthrough advances in this area of research are discussed. We propose a direction for further actions to replenish molecular genetic knowledge about the main drivers of pathological processes in varicose vein disease and to complete the creation of an entire picture of pathogenesis, which, in turn, may serve as a key for the development of treatment options in the future in order to translate research evidence into clinical practice.
\end{abstract}

Keywords: Varicose veins, pathogenesis, genetics, epigenetics, targets

Varicose vein disease (VVD)-the main nosological form of chronic venous diseases-is a multifactorial disease. Risk factors for developing venous pathologies include genetic factors and environmental factors. The risk factors at their basis should be attributed to: (1) predisposing; and/or (2) affecting factors. Genetic, as well as epigenetic, factors seem to be part of both (1) and (2): the mechanical effect leads to a cascade of 
physiological processes, and existing genetic factors can aggravate the clinical situation, and vice versa. However, unfortunately, the genetic factors that are primarily involved in pathological processes are not yet fully understood, and we still have to understand how to formalize the genetic contribution to the phenotype of a person with varicose veins (VVs). The role of genetics in this context can hardly be overestimated, since genetics is one of the constituent parts, in general, of the nucleation of a protein from DNA, where both biochemical and molecular biological processes are involved (i.e., replication, transcription and translation, from what and how protein is synthesized). Moreover, epigenetics can play an equally important role.

\section{HEREDITARY CONSTITUENT OF VARICOSE VEIN PATHOGENESIS-AN OVERVIEW}

The first mention of VVs in the PubMed database dates back to the early 19th century. In the first half of the 20th century, one can find explanations of the hereditary nature of the disease, the most judicious of which was given by the British scientist Ottley ${ }^{[1]}$. Having presented a detailed analysis of a series of fifty cases of VV treatment, the author concluded that inheritance occurs according to the dominant type (even taking into account the cases of the "missed generation" - the absence of manifestation of the disease in one of the generations), because, in general, there was a higher percentage of sufferers than with a recessive defect. In 1949, for example, as a result of histological studies, American scientists Wagner and Herbut drew conclusions about the hereditary factor of VVD; in addition, they were inclined to believe that dilatation of the vein wall precedes valvular insufficiency, which is usually purely functional and secondary ${ }^{[2]}$, which was subsequently supported by other scientists ${ }^{[3,4]}$. The significance of genetic factors in the etiology of VVD was also emphasized in the works of the Danish and Swedish scientists Hauge and Gundersen, who, based on the information they collected about the parents and siblings of 250 patients, concluded that the determination of the disease by one gene is unlikely, and inheritance seems to be multifactorial ${ }^{[5]}$. In 1974 , Czechoslovakian scientists Matousek and Prerovsky estimated the heritability of primary varicose veins is up to $50 \%$ upon assuming the hypothesis of polygenic inheritance ${ }^{[6]}$. Later on, a prominent role of heredity in the development of VVs was demonstrated by the French scientists Cornu-Thenard et al. ${ }^{[7]}$. However, due to the fact that their study did not include examination of siblings or the third generation, they were unable to determine the genetic model of inheritance, and therefore they doubted autosomal dominant and autosomal recessive inheritance models, citing possible "pros" and "cons". A little later, in 1998, Chinese scientists Guo and Guo, based on the results of the genetic analysis of VVD, concluded that in most cases this disease is compatible with an autosomal dominant inheritance of incomplete penetrance, while some of the cases were sporadic, which prompted them to assume a recessive model possible as well ${ }^{[8]}$. Indeed, with an autosomal dominant type of inheritance: (1) the disease is transmitted vertically and is diagnosed in each generation, but, due to incomplete penetrance in the transmission of a trait, sometimes one generation is skipped; (2) phenotypically "normal" family members do not transmit the disease to their offspring; and (3) both men and women can inherit the disease with equal frequency. After analyzing the literature data ${ }^{[9]}$, we tend to believe that the inheritance pattern of VVD is autosomal dominant with incomplete penetrance.

Subsequently, inheritance patterns and the results of family and twin studies were examined in 2003 by the French scientist Pistorius ${ }^{[10]}$, who hypothesized about the possible genetic heterogeneity of VVD, suggesting the existence of different genotypic profiles with a similar phenotype. Many studies by other scientists have also shown a significant genetic contribution to the etiology of VVD, as reported in a review by the New Zealand group of Krysa et al. ${ }^{[11]}$. Since then, genetic research has continued and gained strength and momentum. In recent decades, a lot of genetic research, particularly associative research, has been carried out. 


\section{GENETIC ASSOCIATION STUDIES ON VARICOSE VEIN PATHOGENESIS-AN OVERVIEW}

At the initial stages of the interaction of genetics and phlebology, associative studies of the "case-control" type were carried out, i.e., when the hypothesis is tested whether a genetic marker is found more often in a group of patients than in a control group. Originally, a gene-candidate approach was used, i.e., when one gene or a group of genes was selected, which can participate in the manifestation of some trait with a high probability. These genes were studied using genetic methods known at that time, and many of the studies reviewed provide conflicting data on the clinical significance of genetic associations. In particular, there are several distorting factors that make it difficult to compare between studies. There are different criteria for inclusion and exclusion, subjectivity in diagnosis, the presence of comorbidities, different sources of control groups, size disparity between the groups and differences between ethnic groups. Our 2016 review "The genetic base of chronic venous disease: a review of modern concepts", which is highly scrutinizing from a genetic point of view, provides the detailed information available at that time about the relationship of genetic factors with the development of chronic venous disease ${ }^{[12]}$. Thus, the table "Polymorphic variants/mutations of candidate genes and their associations with chronic venous disease" shows not only the gene, the type of mutation/single nucleotide polymorphism (SNP) and the reference to the article, but also the sample size and the degree of this association, which is decisive for the significance of this association. In the studies performed in our laboratory, it has been shown that, for example, for polymorphic variants of genes AGGF1 (rs13155212, rs7704267) ${ }^{[13]}$, MTHFR (rs1801133) and MTR $(\text { rs 1805087 })^{[14]}$, no associations with the risk of VVD in ethnic Russians were found. There were also no associations found for regulatory SNPs of matrix metalloproteinase genes MMP1 (rs1799750), MMP2 (rs243865), MMP3 (rs3025058) and MMP7 (rs11568818) ${ }^{[15]}$, whereas the rare rs1800562 A allele in the HFE gene leading to the accumulation of iron in the patient's tissues ${ }^{[16]}$ and polymorphic variants $\mathrm{rs} 1035550 \mathrm{C}>\mathrm{T}$ and rs34221221 T>C of the transcription factor FOXC2 gene ${ }^{[17]}$ were associated with an increased risk of VVD. However, none of these associations reached statistical significance after adjustment for multiple comparisons. For the polymorphic locus rs2010963 G > C in the VEGFA gene for the vascular endothelial growth factor, an association with a decreased risk of VVD was revealed, and its significance remained after applying the Bonferroni correction ${ }^{[18]}$. On the sample of ethnic Russians, we also revealed the association of functional SNP rs1024611 in the regulatory region of the $M C P 1$ gene with the increased risk for primary VV development, which was prominent in $\mathrm{C} 2$-class patients, in patients younger than 30 years old at disease onset and in patients with negative anamnesis ${ }^{[19]}$. Thus, there was other evidence for an inflammatory component implication in the pathogenesis of VVs. Later on, we applied a candidate-gene approach to test the implication of 13 functional polymorphisms in the inflammation-related genes to VVD and revealed the association of C allele of the IL6 rs1800795 and the reverse association of T allele of the HIF1A rs11549465, ATTG deletion of the NFKB1 rs28362491 and A allele of the TNF rs3093661 with an increased risk of primary $\mathrm{VVs}^{[20]}$. Notwithstanding, the statistical significance level turned insignificant after correction for multiple comparisons. However, that study had some limitations; therefore, not all associations could be false discoveries.

Entering the era of opportunities and thorough screening of the genome, methylome, transcriptome, proteome, etc., we obtain new unprecedented potential for research on the molecular pathology of venous diseases using agnostic approaches (i.e., free from the original hypothesis) without the need to focus on individual genes. Figuratively, the candidate gene and omics approaches for research can be compared with lighting a street with one lantern or many lanterns, respectively. Obviously, in the latter case, it becomes much easier to find something on it.

One of the biggest genome-wide association studies (GWASs) on VVs was performed by the American 23andMe company scientists who identified a group of 12 SNPs and genes corresponding to them: rs507666 
(ABO), rs966562 (XKR5, ANGPT2, AGPAT5), rs7111987 (ADM, AMPD3), rs11121615 (CASZ1), rs111434909 (ANGPT1), rs145218303 (ARGHAP6), rs6905288 (VEGFA), rs4516218 (PIEZO1), rs4463578 ( ZIC3, FGF13), rs6062618 (SOX18, TCEA2), rs6712038 (PPP3R1, CNRIP1) and rs79607156 (THEG5, ZNF507 $)^{[21]}$. However, those associations were not replicated. Another genome-wide association analysis (combining the discovery and replication stages) for chronic venous disease performed by a German group revealed robust associations within the two loci and genes corresponding to them, namely rs17278665 ( EFEMP1) and rs727139 (KCNH8), and suggestive association within rs2030136 (SKAP2 $)^{[22]}$. Noteworthy, we found the EFEMP1 gene is upregulated in VVs compared to non- $\mathrm{VVs}^{[23]}$. The first large-scale genetic association study for primary varicose veins performed in our laboratory on the Russian population using exome genotyping identified a promising association signal at chromosome 6 within classical major histocompatibility complex class III subregion, with the most statistically significant association being shown in a combined analysis (discovery and replication stages) for polymorphism rs4151657 in the CFB (complement factor B) gene ${ }^{[24]}$, which points to immune system involvement in VV pathogenesis.

Quite a few works have been done to replicate top associations from GWASs for VVD using independent datasets. One of them, performed in our laboratory, aimed to verify the associations revealed by Bell et al. ${ }^{[21]}$ and Ellinghaus et al. ${ }^{[22]}$ using two independent groups of patients: (1) ethnic Russian individuals; and (2) genetic data on a large population-based cohort of British residents obtained from UK Biobank. We also aimed to perform a meta-analysis ${ }^{[25]}$. After combining the original GWAS results and replication studies by a meta-analysis, the following polymorphisms passed a genome-wide significant threshold: rs11121615, rs6712038, rs507666, rs966562, rs7111987, rs6062618, rs6905288, rs111434909, rs4463578, rs111434909 and rs4463578. Most of them are located near or within the genes involved in vascular development, remodeling and inflammation, which implicates these processes in VV pathogenesis. None of those SNPs were from the study of Ellinghaus et al. ${ }^{[22]}$, and the only one that reached a nominal significance level $(P<0.05)$ in the Russian cohort was rs11121615 (CASZ1). Thus, the set of polymorphic variants of genes is indeed not the same in different populations.

Recently, two fairly large bioinformatics (non-experimental) works using modern approaches to big data analysis were published almost in parallel by American and Swedish scientists in 2018 in Circulation ${ }^{[26]}$ and Russian scientists in 2019 in PLoS Genetics ${ }^{[27]}$. After analyzing data from the UK Biobank, the authors of these papers presented a comprehensive genetic and epidemiological study on VVs and identified new clinical and genetic risk factors. Fukaya et al. ${ }^{[26]}$ demonstrated that greater height has a causal role in varicose vein development and discovered a strong genetic correlation between varicose veins and deep vein thrombosis (which, in our opinion, could be because some VVs in their study were not primary since VVD and DVT directly and inversely correlate with each other). Their large-scale GWA of VVs among 337,536 individuals (9577 cases and 327,959 controls) identified the top 30 genetic loci: rs11121615, rs2911463, rs2861819, rs28558138, rs8053350, rs3101725, rs11135046, rs7773004, rs12625547, rs236597, rs7614922, rs73107980, rs7469817, rs2241173, rs816943, rs1061539, rs1549063, rs16828263, rs9719461, rs2263321, rs247749, rs75522736, rs553399706, rs62512472, rs584768, not available SNP on chr6 position 127452639 (build37), rs2089657, rs12594708, rs186005582 and rs192647746. They denoted the genes in closest proximity to the variants (and not only those genes): CASZ1, LBH, PPP3R1, IGSF11, GATA2-AS1, STIM2, TEMN3-AS1, AGGF1, EBF1, SLC12A2, HISTIH3G, HCG9, HLA-B, LINC02549, RSPO3, ALDH8A1, PRKAR1B, CNGB3, DEC1, HDAC7, DAOA,LINC00924, GLG1, CTU2, PIEZO1, KCNJ2, LINCo1152, MAMSTR, NFATC2,ZNF512B ${ }^{[26]}$. Shadrina et al. ${ }^{[27]}$ used genetic association data on VVs for 337,199 individuals (6958 cases and 330,241 controls) and demonstrated direct causal effects of the anthropometric traits, such as height and weight (and not only those traits), as well as plasma levels of immune-related proteins MICB and CD209. Their large-scale GWA identified 12 reliably associated loci that explain 13\% of 
the SNP-based heritability of VVs, prioritizing the most likely causal genes (shown in brackets): rs11121615 (CASZ1), rs2911463 (PIEZO1, CTU2), rs2861819 (PPP3R1, PNO1), rs3101725 (SLC12A2, FBN2, LINC01184), rs11135046 (EBF1), rs28558138 (STIM2), rs7773004 (HFE), rs12625547 (NFATC2), rs2241173 [SOX9, AC005152.3 (LOC102723505)], rs73107980 [COL2A1, RAPGEF3 (EPAC1)], rs9880192 (GATA2) and rs236530 $(K C N J 16, K C N J 2)^{[27]}$. All of those SNPs are the same as those found by Fukaya et al. ${ }^{[26]}$, and only the last two are not in the top 30. Thus, the genetic risk factors found in both works broaden the understanding of VV pathogenesis and can help in further studies to elucidate the mechanisms of the development of the disease.

\section{GENE EXPRESSION STUDIES ON VARICOSE VEIN PATHOGENESIS-AN OVERVIEW}

In addition to genomic studies, one of the ways to "decipher" the possible stages of VV pathogenesis is to study the features of the expression of certain genes in the pathological condition compared to the normal condition. Such differentially expressed genes can be involved in the pathogenesis of the disease by changing the quality of their participation in any functional process or signaling pathway. Common approaches to the search for differential gene expression are both the candidate gene approach and largescale transcriptome analysis, which became possible with the emergence of high-throughput microarray or RNA sequencing technologies-the so-called "omic" studies. Scrutinized literature analysis of gene expression studies (including microarray and mRNA-/tRNA-/lncRNA-sequencing approaches) relevant to VV pathogenesis is presented in two of our works "Differentially expressed genes in varicose vein disease: current state of the problem, analysis of the published data"[28] and "Differentially expressed genes in lower limb varicose vein disease"[29] that complement each other. For example, a change in the expression level of the following genes was shown repeatedly (according to the results of more than one scientific work) in VVD (the arrow direction corresponds to up- or downregulation): $\uparrow$ VEGF (VEGFA), 讴 PTGS2 (COX2), $\uparrow$ $B C L 2, \uparrow B A X, \uparrow B N I P 3, \uparrow H I F 1 A, \downarrow C D 31$ (PECAM-1), $\uparrow$ TGF- $\beta$ (TGFB1), $\downarrow$ TAGLN (SM22-alpha), $\uparrow$ miR-202 (microRNA 202), $\downarrow$ CXCL8 (IL8), $\uparrow$ SEPP1 (SELENOP), $\uparrow$ RGS4, $\downarrow$ FOS (p55, AP-1, C-FOS), $\downarrow$ SOD2 ( $M n-S O D), \downarrow V C L, \uparrow A C T C 1, \uparrow T M E M 158$ (RIS1), $\uparrow$ COL15A1, $\uparrow$ CHRDL2, $\uparrow$ EFEMP1 and $\uparrow$ TIMP1. Therefore, these data can be considered reliable. It can be observed that among them are growth factors and mitochondrial proteins, including those involved in apoptosis. Proteins that belong to the extracellular matrix group play an essential role in varicose transformation of the venous wall. It is worth noting that our works also have made a significant contribution to all of this research.

Since the phenotype of a cell or organism as a whole depends on variable gene expressivity, inheritance of the transcriptional status of genes can lead to epigenetic effects. An essential role in the regulation of gene expression is played by epigenetic mechanisms, which include interactions between genetic variants and environmental factors, cellular reactions and pathological processes. DNA methylation is an epigenetic modification that occurs by attaching a methyl $\left(\mathrm{CH}_{3}\right)$ group to the cytosine bases of DNA without changing its sequence, thereby often changing the expression of genes and affecting their function. If we imagine this figuratively in the form of two clothed hands, then, in the case when there is a methyl group, it is a mitten, and, in the absence of it, it is a glove that allows fingers to freely interact (having shown its activity) with transcription factors and the entire transcriptional machine for further regulation of gene expression. In the case of cytosine methylation within the $\mathrm{CpG}$ loci, especially if they are concentrated in the regulatory regions of the genome, such as promoters (proximal or distal) or enhancers, "gene shutdown" occurs, i.e., suppression of transcription. In the opposite case, if such a CpG locus is not methylated, then the gene is "turned on", i.e., it is transcribed; therefore, mRNA from this gene is produced and the protein is also translated (synthesized) in the cell. Hyper- or hypomethylation can cause both inactivation and autoactivation of genes. If the process affects suppressor genes, then the result is the activation of normally suppressed processes. This can serve as a powerful tool for understanding the molecular mechanisms 
underlying the disease. Particularly in VVD, the following genes are subjected to hypermethylation: ADCY3, $D P E P 2, H R C, P L X N B 1$ and MFAP5 $5^{[30,31]}$. Hypomethylation of the CCN5 (WISP2) gene in $\mathrm{VV}^{[30,32]}$ induces its activity, which, in turn, potentiates TGF- $\beta$. The result is the remodeling of the extracellular matrix. Moreover, changes in DNA methylation at specific loci as well as other epigenetic marks (histone modifications and non-coding RNAs) are heritable ${ }^{[33,34]}$. For instance, it was demonstrated that genetically identical mice may differ in the degree of their tails' kinkiness, so that mysterious epigenetic marks responsible for variable expressivity are inherited between generations ${ }^{[35]}$.

Our study using large-scale microarray analysis of transcriptome and methylome identified sets of differentially expressed genes and differentially methylated DNA loci in VVs compared to non-varicose vein ${ }^{[30]}$. Using independent methods and replicative sample sets, we already validated some of these data. By dint of bioinformatics analysis performed by our colleagues from Germany, the relationship of such master regulators was shown, i.e., those genes whose products are likely to participate in the pathogenesis and possibly trigger the processes of vein wall remodeling and its varicose transformation. These are genes for the extracellular matrix organization (including collagens and tissue inhibitors of metalloproteinases), cell adhesion and vascular morphogenesis. Figure 1 schematically represents (of course, not completely) the interplay of the genetic master regulators contributing to VVD development.

\section{WHERE ARE WE NOW IN TERMS OF LEARNING, IN TERMS OF UNDERSTANDING, AND WHERE ARE WE GOING? A CHALLENGE FOR THE FUTURE}

Molecular events occurring in the pathogenesis of VVs are indeed known fragmentarily, and their sequence is not always clear: what is the cause and what is the consequence. Many of the heroes involved in certain events are still behind the scenes. By studying the features of gene expression and methylation in the pathological condition, as well as other processes, researchers are able to decipher the mechanisms and various stages of pathogenesis step by step.

Realizing that, after all, the pathogenesis of chronic venous diseases is a very complex process, it should be borne in mind that even a single gene effect can cause little influence. Therefore, studies with a large number of patients are required before drawing any conclusions. In addition, the impact of a particular polymorphism will depend on genotype-environment interactions that may be specific to a given patient population. Genome-wide research has indeed made a significant contribution to the discovery of genes associated with venous pathology, but there are still puzzles that need to be pieced together. Multicenter international studies and the formation of consortia will help to clarify the connection between genetic markers and various pathological components of chronic venous diseases, including VVD. When efforts come together, these will not only be large samples, but they will also be synchronized according to inclusion-exclusion criteria, research methodology and interpretation of the analysis results, and they will take into account the ethnicity of the analyzed groups.

It is expedient to draw the attention of readers to the following fact: the absence of the relative levels of genes' expression in the veins in relation to other organs and tissues. In one of the largest databases of biological and medical research, NCBI (PubMed/Gene), there is no information on the levels of gene expression, not only in the veins but even in the vessels! Only 27 organs and tissues are indicated there (heart, lungs, liver, kidneys, etc.). In another database-UCSC Genome Browser on human-which provides the gene expression profiles in 54 organs and tissues, one can already find information on gene expression in the arteries (however, only in three kinds-aorta, coronary and tibial arteries), but the veins are not there yet. If we imagine it is possible to add new missing data, then in perhaps the future it will be possible to get a more complete picture. Of course, such voluminous studies on large samples of people require large 


\section{Predisposing and affecting factors for VVD development}

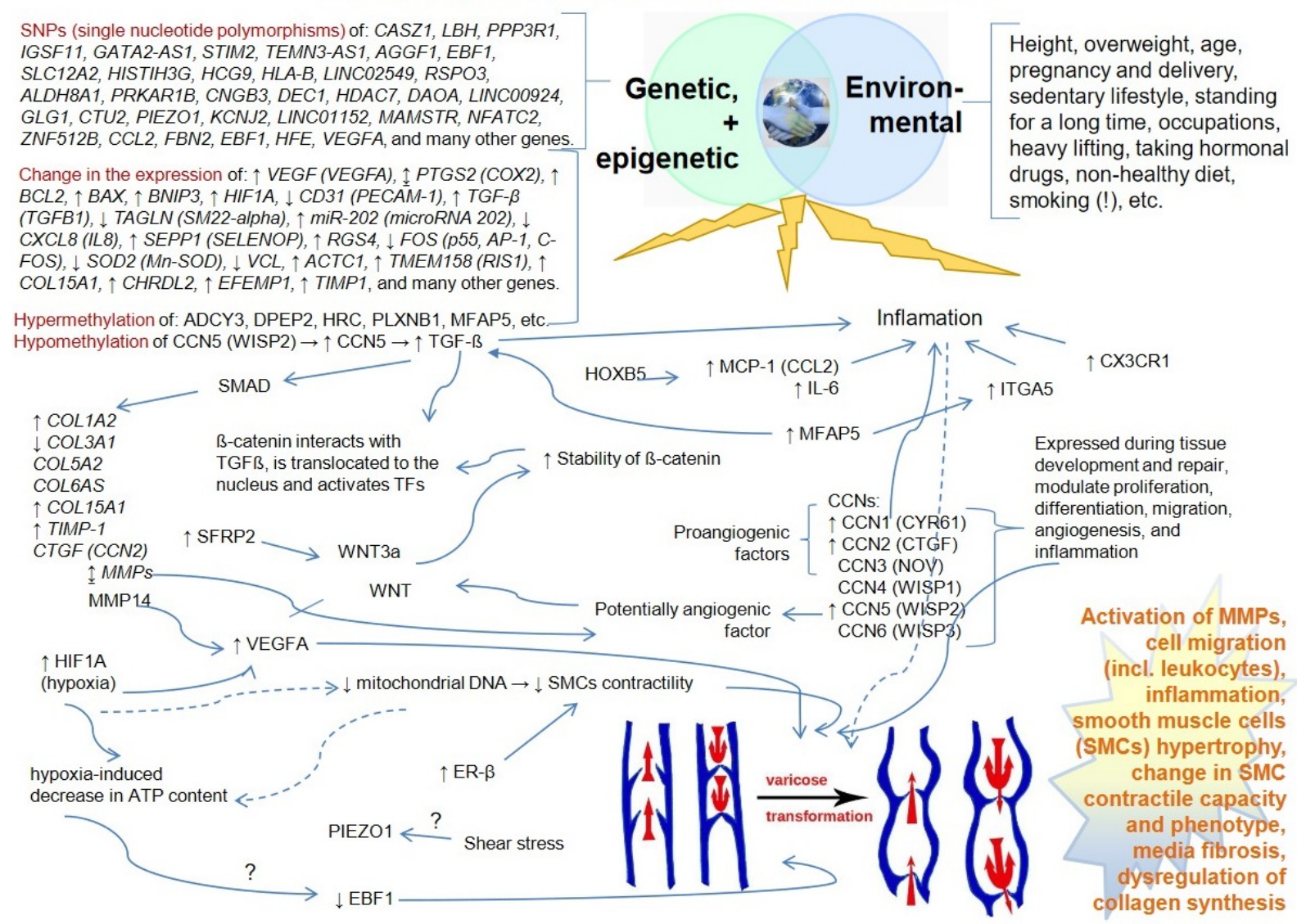

Figure 1. Schematic representation of the interplay of the genetic master regulators contributing to VVD development.

investments and efforts of not one person, but collectives. However, without such data for veins (relative to other organs and tissues), further research on venous-specific action, for example, of certain medications, will be very difficult. Recently, it was shown that mitochondrial DNA copy number (mtDNA-CN) was inversely associated with incident and prevalent cardiovascular disease outcomes in 21,870 participants from three independent cohorts $^{[36]}$. Shortly after, in our laboratory, we found that mtDNA-CN was decreased in varicose vein $v s$. non-varicose vein tissue samples ${ }^{\left[{ }^{[3]}\right.}$. Then, Castellani et al. ${ }^{[38]}$ demonstrated across multiple independent cohorts that changes in mtDNA-CN influence nuclear DNA methylation at specific $\mathrm{CpG}$ loci and result in differential expression of specific genes that may impact human health and disease (namely, cardiovascular disease and all-cause mortality) via altered cell signaling ${ }^{[38]}$. Understanding the mechanisms of mitochondrial and nuclear communication may shed light on the complex etiology of the disease, as well as the implications of therapeutic strategies to increase mitochondrial function. The fact that some drugs used in VVD treatment show their benefits in treating arterial diseases as well may serve as auxiliary evidence for the common molecular-genetic pathways in the pathogenesis of vascular diseases. A significant phlebotonic effect seems to be improbable without any impact on arterial smooth muscles and blood pressure ${ }^{[39]}$. Indeed, horse chestnut extract contracts (through serotonin receptors, at least partly) both veins and arteries, but it is more potent in inducing venocontraction ${ }^{[40]}$. A pharmacological vasoactive agent, diosmin, is capable of inhibiting inflammatory pathways since it simultaneously influences proangiogenic/anti-angiogenic balance by an increase of anti-angiogenic factors and reducing the level of proangiogenic factors in blood plasma (TNF-alpha, VEGF-A and VEGF-C, angiostatin, IL-6, FGF2 and 
PLG ${ }^{[41]}$. Bioflavonoids found in citrus bioflavonoid extract, grape seed extract, pine bark extract and green tea extract participate in the regulation of human aortic smooth muscle cell-mediated contraction and have a strong potential for counteracting pathophysiological effects of angiotensin II-the leading mediator of clinical systemic hypertension ${ }^{[42]}$. Anti-hypertensive effects of diosmin (namely, compromised NO-synthase inhibitor induced cardiac infarcts, hyaline arteriopathy and fibrinoid necrosis), presumably because of its activity in elimination of superoxide anions, were demonstrated in a rat model $^{[43]}$. Peripheral arterial disease may also be treated with Sulodexide, which prevents cardiovascular events after myocardial infarction and exerts the relief of intermittent claudication ${ }^{[44]}$.

In 2020, a Russian group of scientists performed a scrutinizing review based on the literature data and their own works and postulated that: (a) primary varicose transformation of superficial veins develops as a result of remodeling of their walls; (b) vein wall remodeling is based on a complex of molecular processes determined by genetic predisposition; (c) vein wall remodeling is reversible, i.e., the dilated and altered vein can return to its original ("healthy") state; and (d) varicose veins can probably be successfully cured pharmacologically with no surgical interventions needed ${ }^{[45]}$. Table 1 , compiled on the basis of data from Kharkevich (2004) ${ }^{[39]}$, Maggioli ${ }^{[46]}$ (2016), Ramelet et al. ${ }^{[47]}$ (2017) and Mansilha and Sousa ${ }^{[48]}$ (2018), as well as other sources, is a kind of generalization of the treatment options for patients suffering from chronic venous diseases.

Apparently, not all the works devoted to the investigation of phlebotonics' efficacy are cited in this table. Martinez-Zapata et al..$^{[72]}$ performed a very thorough (237 pages) review "Phlebotonics for venous insufficiency" on randomized, double-blind, placebo-controlled trials where the efficacy of phlebotonics (rutosides, diosmine, hidrosmine, calcium dobesilate, aminaftone, disodium flavodate, chromocarbe, Centella asiatica, French maritime pine bark extract and grape seed extract) was assessed. The authors concluded that there was "moderate-certainty evidence that phlebotonics probably reduce (o)edema slightly, compared to placebo; moderate-certainty evidence of little or no difference in quality of life; and low-certainty evidence that these drugs do not influence ulcer healing; moderate-certainty evidence suggests that phlebotonics are probably associated with a higher risk of adverse events than placebo"[72]. One possible reason that the desired efficacies were not observed in many clinical trials could be because, in order to have an effect, many flavonoids should be metabolized due to the intestine microflora ${ }^{[46,43]}$. What if the patient's microflora is impaired? Does that mean all those efforts might be in vain? It is known that one of the most popular drugs in phlebological practice - micronized purified flavonoid fraction - is more effective as a complex substance rather than its components applied separately ${ }^{[73]}$. Nowadays, new possible venoactive drugs are being investigated. Recently, using a mouse model, Lust et al. ${ }^{[74]}$ showed that diclofenac (COX-2, or cyclooxygenase, inhibitor) is capable of attenuating venous remodeling in vivo $^{[74]}$. We are likely entering the era of research on new potential substances targeting the main drivers of pathological processes in varicose vein disease.

\section{CONCLUSION}

In recent decades, the studies on varicose veins have paid much attention to its genetic constituent. In this perspective, we provide a critical overview and literature analysis on the heredity of varicose veins, genetic association studies, gene expression and epigenetic studies and point out the gaps existing in the field. We hope that the generalized information given will be useful not only for fundamental scientific researchers, but also for clinicians, and will be further used in phlebological practice. Revealing the genetic basis of venous diseases can help to clarify the mechanisms of pathogenesis, and their understanding, in turn, can help to develop new methods of prevention and treatment of varicose veins. Of note, for disease risk assessment, epigenetic factors and their heritability should be considered as well. Perhaps in our century 
Table 1. Main venoactive drugs (venoprotective and venoconstrictor/venotonic) used for CVD ${ }^{\star}$ treatment

1. Main venoactive drugs (venoprotective and venoconstrictor/venotonic) used for CVD treatment

[Grades, if

Group

Registered as: trade name [country]

Effects

Ref.

Mixed-action drugs (venoprotective and venoconstrictor/venotonic)

Micronized purified $90 \%$ micronized diosmin and Daflon ${ }^{\circ}$ [France], Detralex [France, Russia], Detravenol [Russia],

flavonoid fraction $10 \%$ flavonoids (hesperidin,

(MPFF) $[A]$ diosmetin, linarin, and

Venarus [Russia], Angiorus [Russia], Linfadren [Italy]; Ardium

[France], Alvenor [Bangladesh], Arvenum [Italy], Capiven

[Denmark], Elatec [Mexico], Variton [Mexico], Flebotropin

[Argentina], Venitol ${ }^{\circ}$ South Korea], VEDIPAL [Argentina, Chile,

Puerto Rico, Spain, Guatemala, etc.], Venolex [Georgia], Flebaven

[Russia]

Diosmiplex Diosmin glycoside (flavonoid) + Vasculera $^{\text {TM }}$ (USA)

Alka4-complex

Increases venous tone, protects against inflammation-related

valve damage, decreases capillary permeability, improves

capillary resistance, increases lymphatic drainage and

alleviates leg (o)edema, improves skin trophic disorders and

ulcer healing, relieves symptoms related to CVD at all stages

and improves QoL ; more effective as a complex substance

rather than its components applied separately

Restores toward normal the metabolic aspects of $\mathrm{CVI}$

including modulation of venous tone and capillary resistance, management of lymphatic drainage, and inflammation in the microcirculation; reduces acidosis under extreme exercise loads

Diosmin [C] Flavonoid

Phlebodia 600* [France], Diovenor [France], Dio-PP [Hungary], VENO V [Portugal], Venosmine [ltaly, Hong Kong]

Prolongs the vasoconstrictor effect of norepinephrine on the

vein wall, increases venous tone, reduces venous capacitance,

distensibility, and stasis; improves lymphatic drainage;

improves all CEAP stages of CVD including venous ulcers, and improves QoL

Horse chestnut seed Saponosides extracts $[B]$

Ruscus extracts [B] Saponosides; Ruscosides (Butcher's broom)

Grape Seed Extract Procyanidolic oligomers,

precursors of

tannins

Glucofuranoside Synthetic drug

derivative

II. Venoprotective drugs

Rutin and its Bioflavonoids; rutosides

derivatives (oxerutin

$[\mathrm{A}]$; troxerutin [C])

Ginkgo biloba leaf Quercetol, rutoside (leaf)

extracts $[C]$
Horse chestnut extract fluid [Russia], Escizane and Aescine [Russia] Aescin (escin) [Poland, Slovakia, Taiwan], Esceven (escin, heparin) [Poland], Aescusan 20 [Germany], Aescin-Teva [Czech Republic] Reparil' (diethylamine salicylate, escin) [Italy, Belgium, Brazil, etc.], Aescusan [Germany], Aesflazidum [Russia], Venoplant ' [Germany], Venostasin [Austria], Anavenol Zentiva (dihydroergocristine mesylate + esculin + rutin) [Czech Republic]

Cyclo-3 fort (broomstick extract + hesperidin methylchalcone + ascorbic acid) [Poland], Phlebodril [Germany]

Endotelon [France], AS195, Antistax

(red vine leaf extract) [Germany]

Glyvenol (tribenoside) [Switzerland, Germany]

Anti-inflammatory, anti-(o)edematous, and venotonic effects may be an alternative for compression stockings

$[40,60,62,63]$

Antioxidant and anti-inflammatory properties, as well as significant venular constriction effect

Due to its anti-oxidant properties can strengthen blood vessels $[63,66,67]$ and reduce inflammation; maintains slide circulation and

improves the tired heavy achy feeling that results from venous insufficiency

Anti-inflammatory and analgesic effects; decreases capillary permeability Republic], Troxevasin (troxerutin) [Bulgaria], Cerutin [Lebanon, Poland], Rutoscorbin [Lithuania, Poland, Romania]

Bilobil, Ginkio, Memoplant; Ginkor Fort (Ginkgo biloba extract + heptaminol hydrochloride + troxerutin) [France] 


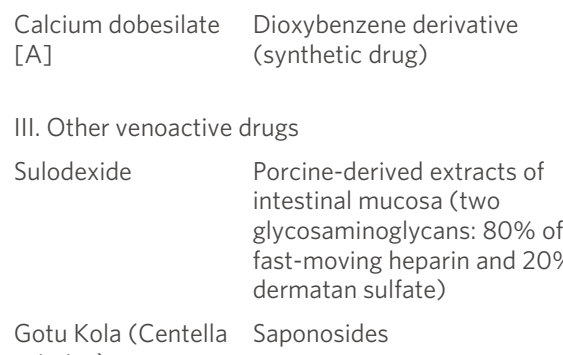

${ }^{\$}$ Grade of Recommendations (according to Ramelet et al. ${ }^{[47]}$ ) depends on the conduction of the Randomized Controlled Trial (RCT): (a) RCT with large sample sizes, valid meta-analyses (Grade A): (b) RCT with small sample size (Grade B); and (c) other controlled trials, no RCTs (Grade C). "Esculin is a coumarin glycoside from the leaves and bark of horse chestnut (glycone - glucose, aglycone - 6,7-dioxycoumarin). Heptaminol hydrochloride tones up varicose veins and has a cardio-stimulating effect. Some venoconstrictor/venotonic only drugs [such as $\alpha$-adrenergic agonists fentanyl (Ethylephrine; Actiq, Duragesic, Sublimaze) and midodrine [Gutron; Orvaten, ProAmatine]; dihydrogenated ergot alkaloids (Dihydroergotoxin, Dihydroergotamine, Dihydroergocriptine, Vazobral)] were not included in this table due to their irrelevance for CVD treatment. "CVD: Chronic venous disease. QoL: quality of life. CVI: chronic venous insufficiency.

some miracle remedy will be invented, even if not universal, but which will really be able to help patients.

\section{DECLARATIONS}

\section{Acknowledgments}

The authors are grateful to the native English speakers Holly Jacob (Texas A\&M University, USA) and Christine Tierney (Houston Community College, USA) for grammar checking assistance and thorough text revision.

\section{Authors' contributions}

Made substantial contributions to conception and design of the study: Smetanina MA, Shevela AI, Gavrilov KA, Filipenko ML

Performed literature analysis and writing the manuscript: Smetanina MA

Helped with data interpretation relating to clinical part: Shevela AI, Gavrilov KA

Helped with data acquisition, as well as provided administrative, technical, and material support: Filipenko ML

\section{Availability of data and materials}

Not applicable.

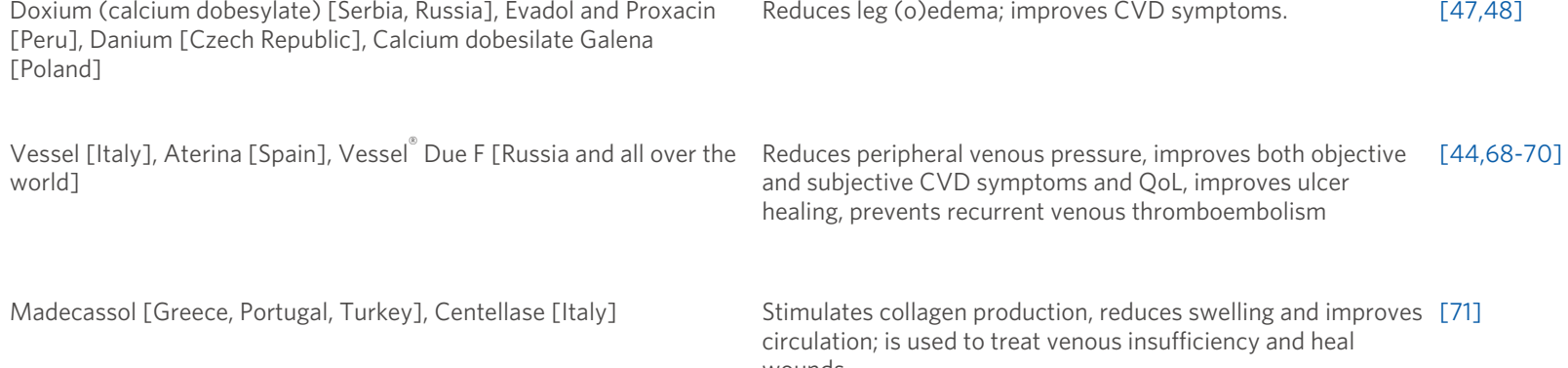

$[47,48]$ 


\section{Financial support and sponsorship}

This work was supported by the Program of Fundamental Scientific Research of the Russian Federation (PFSR RF) “Fundamental Basics of Health Preservation" (No. 121031300045-2).

\section{Conflicts of interest}

All authors declared that there are no conflicts of interest.

\section{Ethical approval and consent to participate}

Not applicable.

\section{Consent for publication}

Not applicable.

\section{Copyright}

(c) The Author(s) 2021.

\section{REFERENCES}

1. Ottley C. Heredity and varicose veins. Br Med J 1934;1:528. DOI PubMed PMC

2. Wagner FB, Herbut PA. Etiology of primary varicose veins. Am J Surg 1949;78:876-80. DOI PubMed

3. Vanhoutte PM, Corcaud S, de Montrion C. Venous disease: from pathophysiology to quality of life. Angiology 1997;48:559-67. DOI PubMed

4. Meissner MH, Gloviczki P, Bergan J, et al. Primary chronic venous disorders. J Vasc Surg 2007;46 Suppl S:54S-67S. DOI PubMed

5. Hauge M, Gundersen J. Genetics of varicose veins of the lower extremities. Hum Hered 1969;19:573-80. DOI PubMed

6. Matousek V, Prerovský I. A contribution to the problem of the inheritance of primary varicose veins. Hum Hered 1974;24:225-35. DOI PubMed

7. Cornu-Thenard A, Boivin P, Baud JM, De Vincenzi I, Carpentier PH. Importance of the familial factor in varicose disease. Clinical study of 134 families. J Dermatol Surg Oncol 1994;20:318-26. DOI PubMed

8. Guo Q, Guo C. Genetic analysis of varicose vein of lower extremities. Zhonghua Yi Xue Yi Chuan Xue Za Zhi 1998;15:221-3. (in Chinese) PubMed

9. Serra R, Buffone G, de Franciscis A, et al. A genetic study of chronic venous insufficiency. Ann Vasc Surg 2012;26:636-42. DOI PubMed

10. Pistorius MA. Chronic venous insufficiency: the genetic influence. Angiology 2003;54 Suppl 1:S5-12. DOI PubMed

11. Krysa J, Jones GT, van Rij AM. Evidence for a genetic role in varicose veins and chronic venous insufficiency. Phlebology 2012;27:329-35. DOI PubMed

12. Smetanina MA, Shadrina AS, Zolotukhin IA, Filipenko MI. The genetic base of chronic venous disease: a review of modern concepts. Flebol 2016;10:199. (in Russian). DOI

13. Shadrina AS, Smetanina MA, Sevost'ianova KS, et al. Polymorphic variants rs 13155212 (T/C) and rs 7704267 (G/C) in the AGGF1 gene and risk of varicose veins of the lower extremities in the population of ethnic Russians. Bull Exp Biol Med 2016;161:698-702. DOI PubMed

14. Shadrina AS, Sevost'ianova KS, Shevela AI, et al. Polymorphisms in the MTHFR and MTR genes and the risk of varicose veins in ethnical Russians. Biomarkers 2016;21:619-24. DOI PubMed

15. Shadrina AS, Smetanina MA, Sevost'yanova KS, et al. Polymorphism of matrix metalloproteinases genes MMP1, MMP2, MMP3, and MMP7 and the risk of varicose veins of lower extremities. Bull Exp Biol Med 2017;163:650-4. DOI PubMed

16. Sokolova EA, Shadrina AS, Sevost'ianova KS, et al. HFE p.C282Y gene variant is associated with varicose veins in Russian population. Clin Exp Med 2016;16:463-70. DOI PubMed

17. Shadrina AS, Smetanina MA, Sokolova EA, et al. Association of polymorphisms near the FOXC2 gene with the risk of varicose veins in ethnic Russians. Phlebology 2016;31:640-8. DOI PubMed

18. Shadrina AS, Smetanina MA, Sokolova EA, et al. Allele rs2010963 C of the VEGFA gene is associated with the decreased risk of primary varicose veins in ethnic Russians. Phlebology 2018;33:27-35. DOI PubMed

19. Shadrina AS, Smetanina MA, Sevost'ianova KS, et al. Functional polymorphism rs 1024611 in the MCP1 gene is associated with the risk of varicose veins of lower extremities. J Vasc Surg Venous Lymphat Disord 2017;5:561-6. DOI PubMed

20. Shadrina A, Voronina E, Smetanina M, et al. Polymorphisms in inflammation-related genes and the risk of primary varicose veins in ethnic Russians. Immunol Res 2018;66:141-50. DOI PubMed

21. Bell RK, Durand EY, McLean CY, Eriksson N, Tung JY, et al. A large scale genome wide association study of varicose veins in the 23 andMe cohort. In: The 64th Annual Meeting of The American Society of Human Genetics; 2014 Oct 18-22; San Diego, USA: ASHG. Paper no. 2082M; p. 487.

22. Ellinghaus E, Ellinghaus D, Krusche P, et al. Genome-wide association analysis for chronic venous disease identifies EFEMP1 and 
KCNH8 as susceptibility loci. Sci Rep 2017;7:45652. DOI PubMed PMC

23. Shevela AI, Gavrilov KA, Plotnikova EY, Sevostianova KS, Filipenko ML, Smetanina MA. Altered expression of the extracellular matrix related genes COL15A1, CHRDL2, EFEMP1, and TIMP1 in Varicose Veins. Eur J Vasc Endovasc Surg 2020;60:e75-6. DOI

24. Shadrina A, Tsepilov Y, Sokolova E, et al. Genome-wide association study in ethnic Russians suggests an association of the MHC class III genomic region with the risk of primary varicose veins. Gene 2018;659:93-9. DOI PubMed

25. Shadrina A, Tsepilov Y, Smetanina M, et al. Polymorphisms of genes involved in inflammation and blood vessel development influence the risk of varicose veins. Clin Genet 2018;94:191-9. DOI PubMed

26. Fukaya E, Flores AM, Lindholm D, et al. Clinical and genetic determinants of varicose veins. Circulation 2018;138:2869-80. DOI PubMed PMC

27. Shadrina AS, Sharapov SZ, Shashkova TI, Tsepilov YA. Varicose veins of lower extremities: Insights from the first large-scale genetic study. PLoS Genet 2019;15:e1008110. DOI PubMed PMC

28. Smetanina MA, Shadrina AS, Zolotukhin IA, Seliverstov EI, Filipenko ML. Differentially expressed genes in varicose veins disease: current state of the problem, analysis of the Published Data. Flebol 2017;11:190. (in Russian). DOI

29. Smetanina M, Sipin F, Seliverstov E, Zolotukhin I, Filipenko M. Differentially Expressed genes in lower limb varicose vein disease. Flebol 2020;14:122. (in Russian). DOI

30. Smetanina MA, Kel AE, Sevost'ianova KS, et al. DNA methylation and gene expression profiling reveal MFAP5 as a regulatory driver of extracellular matrix remodeling in varicose vein disease. Epigenomics 2018;10:1103-19. DOI PubMed

31. Smetanina MA, Sipin FA, Sevostyanova KS, Khrapov EA, Zolotukhin IA, Filipenko ML. Two CpG loci in the regulatory regions of the MFAP5 gene are hypomethylated in varicose veins. In: ABSTRACTS of the International Union of Phlebology Chapter Meeting; 2019 Aug 25-27; Krakow, Poland. Phlebological Review 2019;1:23-4.

32. Smetanina MA, Shevela AI, Gavrilov KA, Filipenko ML. Modified methylation of the DNA loci related to the genes HRC, DPEP2, and CCN5 in varicose veins. In: BOOK OF ABSTRACTS of the 13th St. Petersburg Venous Forum (Christmas Meetings); 2020 Dec 4-5; St. Petersburg, Russia. ADVANCED PROBLEMS IN PHLEBOLOGY; 2020. p. 11-12.

33. Lim JP, Brunet A. Bridging the transgenerational gap with epigenetic memory. Trends Genet 2013;29:176-86. DOI PubMed PMC

34. Legoff L, D'Cruz SC, Tevosian S, Primig M, Smagulova F. Transgenerational Inheritance of Environmentally Induced Epigenetic Alterations during Mammalian Development. Cells 2019;8:1559. DOI PubMed PMC

35. Bradbury J. Human epigenome project--up and running. PLoS Biol 2003;1:E82. DOI PubMed PMC

36. Ashar FN, Zhang Y, Longchamps RJ, et al. Association of mitochondrial DNA copy number with cardiovascular disease. JAMA Cardiol 2017;2:1247-55. DOI PubMed PMC

37. Smetanina MA, Sevost'ianova KS, Shirshova AN, et al. Quantitative and structural characteristics of mitochondrial DNA in varicose veins. In: SCIENTIFIC PROGRAMME AND BOOK OF ABSTRACTS of the 20th Annual Meeting of the European Venous Forum; 2019 June 27-29; Zurich, Switzerland. Edizioni Minerva Medica;24.

38. Castellani CA, Longchamps RJ, Sumpter JA, et al. Mitochondrial DNA copy number can influence mortality and cardiovascular disease via methylation of nuclear DNA CpGs. Genome Med 2020;12:84. DOI PubMed PMC

39. Kharkevich DA. Venotropic (phlebotropic) agents. Eksp Klin Farmakol 2004;67:69-77. (in Russian) [PMID: 15079914] PubMed

40. Felixsson E, Persson IA, Eriksson AC, Persson K. Horse chestnut extract contracts bovine vessels and affects human platelet aggregation through 5-HT(2A) receptors: an in vitro study. Phytother Res 2010;24:1297-301. DOI PubMed

41. Feldo M, Wójciak-Kosior M, Sowa I, et al. Effect of Diosmin Administration in Patients with Chronic Venous Disorders on Selected Factors Affecting Angiogenesis. Molecules 2019;24:3316. DOI PubMed PMC

42. Ivanov V, Roomi MW, Kalinovsky T, Niedzwiecki A, Rath M. Bioflavonoids effectively inhibit smooth muscle cell-mediated contraction of collagen matrix induced by angiotensin II. J Cardiovasc Pharmacol 2005;46:570-6. DOI PubMed

43. Zheng Y, Zhang R, Shi W, et al. Metabolism and pharmacological activities of the natural health-benefiting compound diosmin. Food Funct 2020;11:8472-92. DOI PubMed

44. Coccheri S, Mannello F. Development and use of sulodexide in vascular diseases: implications for treatment. Drug Des Devel Ther 2013;8:49-65. DOI PubMed PMC

45. Zolotukhin IA, Porembskaya OY, Smetanina MA, Sazhin AV, Filipenko ML, Kirienko AI. Varicose veins: on the verge of discovering the cause? Annals RAMS 2020;75:36-45. (in Russian). DOI

46. Maggioli A. Chronic venous disorders: pharmacological and clinical aspects of micronized purified flavonoid fraction. Phlebolymphology 2016;23:82-91.

47. Ramelet AA. Venoactive Drugs. In: Goldman MP, Weiss RA, editors. Sclerotherapy 6th ed. Treatment of Varicose and Telangiectatic Leg Veins. Elsevier; 2017. pp. 426-34. DOI

48. Mansilha A, Sousa J. Pathophysiological Mechanisms of Chronic Venous Disease and Implications for Venoactive Drug Therapy. Int J Mol Sci 2018;19:1669. DOI PubMed PMC

49. Paysant J, Sansilvestri-Morel P, Bouskela E, Verbeuren TJ. Different flavonoids present in the micronized purified flavonoid fraction (Daflon $500 \mathrm{mg}$ ) contribute to its anti-hyperpermeability effect in the hamster cheek pouch microcirculation. Int Angiol 2008;27:81-5. [PMID: 18277344]. PubMed

50. Yanushko VA, Bayeshko AA, Sushkov SA, Nebylitsyn YS, Nazaruk AM. Benefits of MPFF on primary chronic venous diseaserelated symptoms and quality of life: the DELTA study. Phlebolymphology 2014;21:146-51.

51. Graças C de Souza M, Cyrino FZ, de Carvalho JJ, Blanc-Guillemaud V, Bouskela E. Protective Effects of Micronized Purified Flavonoid Fraction (MPFF) on a Novel Experimental Model of Chronic Venous Hypertension. Eur J Vasc Endovasc Surg 2018;55:694-702. DOI PubMed 
52. Kakkos SK, Nicolaides AN. Efficacy of micronized purified flavonoid fraction (Daflon $®$ ) on improving individual symptoms, signs and quality of life in patients with chronic venous disease: a systematic review and meta-analysis of randomized double-blind placebocontrolled trials. Int Angiol 2018;37:143-54. DOI PubMed

53. Rodnyansky DV, Fokin AA. [Diosmin-containing phlebotropic drugs in varicose eczema]. Angiol Sosud Khir 2019;25:88-92. DOI PubMed

54. Kurginyan HM, Raskin VV. Modern view on the therapy of chronic venous insufficiency with micronized purified flavonoid fraction. Cardiovasc Ther Prev 2020;19:2592.

55. Ponomarev ÉA, Strepetov NN, Sotnikov IE, et al. [Use of Detravenol in treatment of chronic venous insufficiency of lower limbs]. Angiol Sosud Khir 2020;26:95-102. DOI PubMed

56. Raffetto JD, Eberhardt RT, Dean SM, Ligi D, Mannello F. Pharmacologic treatment to improve venous leg ulcer healing. J Vasc Surg Venous Lymphat Disord 2016;4:371-4. DOI PubMed

57. Bush R, Comerota A, Meissner M, Raffetto JD, Hahn SR, Freeman K. Recommendations for the medical management of chronic venous disease: The role of Micronized Purified Flavanoid Fraction (MPFF). Phlebology 2017;32:3-19. DOI PubMed

58. Melin MM, Dean SM. RE: A literature review of pharmacological agents to improve venous leg ulcer healing. Letter to the Editor. Wounds 2020;32:A10.

59. U.S. Department of Health \& Human Services, National Institutes of Health, NCATS. Inxight: Drugs. Vasculera. Available from: https://drugs.ncats.io/drug/Z7R65IFU98. [Last accessed on 12 Mar 2021].

60. Casili G, Lanza M, Campolo M, et al. Therapeutic potential of flavonoids in the treatment of chronic venous insufficiency. Vascul Pharmacol 2021;137:106825. DOI PubMed

61. U.S. Department of Health \& Human Services, National Institutes of Health, NCATS. Inxight: Drugs. Diosmin. Available from: https://drugs.ncats.io/drug/7QM776WJ5N. [Last accessed on 12 Mar 2021].

62. Sirtori CR. Aescin: pharmacology, pharmacokinetics and therapeutic profile. Pharmacol Res 2001;44:183-93. DOI PubMed

63. Stücker M, Debus ES, Hoffmann J, et al. Consensus statement on the symptom-based treatment of chronic venous diseases. J Dtsch Dermatol Ges 2016;14:575-83. DOI PubMed

64. Peralta GR, Arévalo Gardoqui J, Llamas Macías FJ, Navarro Ceja VH, Mendoza Cisneros SA, Martínez Macías CG. Clinical and capillaroscopic evaluation in the treatment of chronic venous insufficiency with Ruscus aculeatus, hesperidin methylchalcone and ascorbic acid in venous insufficiency treatment of ambulatory patients. Int Angiol 2007;26:378-84. PubMed

65. Almeida Cyrino FZG, Balthazar DS, Sicuro FL, Bouskela E. Effects of venotonic drugs on the microcirculation: Comparison between Ruscus extract and micronized diosmine1. Clin Hemorheol Microcirc 2018;68:371-82. DOI PubMed

66. Kiesewetter H, Koscielny J, Kalus U, et al. Efficacy of orally administered extract of red vine leaf AS 195 (folia vitis viniferae) in chronic venous insufficiency (stages I-II). A randomized, double-blind, placebo-controlled trial. Arzneimittelforschung 2000;50:10917. DOI PubMed

67. Rabe E, Stücker M, Esperester A, Schäfer E, Ottillinger B. Efficacy and tolerability of a red-vine-leaf extract in patients suffering from chronic venous insufficiency--results of a double-blind placebo-controlled study. Eur J Vasc Endovasc Surg 2011;41:540-7. DOI PubMed

68. Elleuch N, Zidi H, Bellamine Z, Hamdane A, Guerchi M, Jellazi N; CVD study investigators. Sulodexide in Patients with Chronic Venous Disease of the Lower Limbs: Clinical Efficacy and Impact on Quality of Life. Adv Ther 2016;33:1536-49. DOI PubMed PMC

69. Chupin AV, Katorkin SE, Katel'nitskiĭ II, et al. Sulodexide in treatment of chronic venous insufficiency. Results of the All-Russian multicenter programme ACVEDUCT. Angiol Sosud Khir 2018;24:47-55. (in Russian). PubMed

70. Carroll BJ, Piazza G, Goldhaber SZ. Sulodexide in venous disease. J Thromb Haemost 2019;17:31-8. DOI PubMed

71. Gohil KJ, Patel JA, Gajjar AK. Pharmacological Review on Centella asiatica: A Potential Herbal Cure-all. Indian J Pharm Sci 2010;72:546-56. DOI PubMed PMC

72. Martinez-Zapata MJ, Vernooij RW, Simancas-Racines D, et al. Phlebotonics for venous insufficiency. Cochrane Database Syst Rev 2020;11:CD003229. DOI PubMed

73. Karetová D, Suchopár J, Bultas J. Diosmin/hesperidin: a cooperating tandem, or is diosmin crucial and hesperidin an inactive ingredient only? Vnitr Lek 2020;66:97-103. PubMed

74. Lust L, Kuk H, Kohlhaas J, Sticht C, Korff T. Inhibition of cyclooxygenase activity by diclofenac attenuates varicose remodeling of mouse veins. Vessel Plus 2021;5:7. DOI 